Supporting Information

\title{
Planar, Energetic, $\pi-\pi$-Stacked Compound with Weak Interactions Resulting in a High-Impact- and Low-Friction-Sensitive, Safer, Primary Explosive
}

\author{
Weijing Zhang, Tong Li, Bo Zhang, Lin Wang, Tonglai Zhang*, Jianguo Zhang
}

State Key Laboratory of Explosion Science and Technology, School of Mechatronical Engineering, Beijing Institute of Technology, 5 South Zhongguancun Street, Beijing 100081, P. R. China.

* Corresponding Author: Prof. Tonglai Zhang

Email:

Tonglai Zhang: ztlbit@bit.edu.cn

Weijing Zhang: zwj370512536@163.com 


\section{Table of Contents}

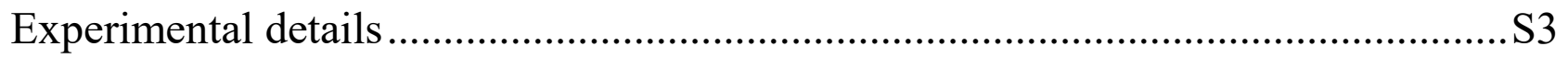

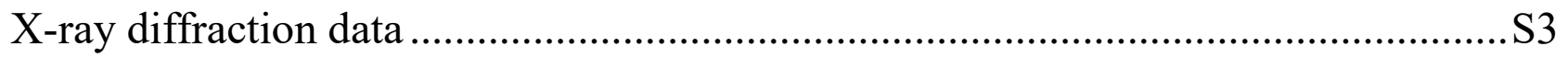

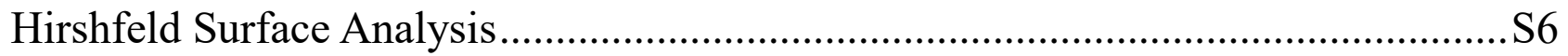

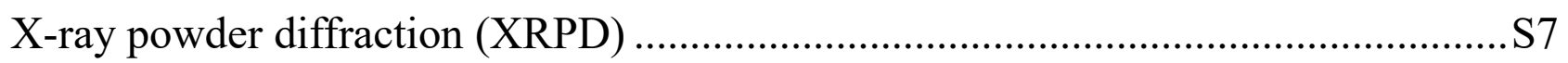

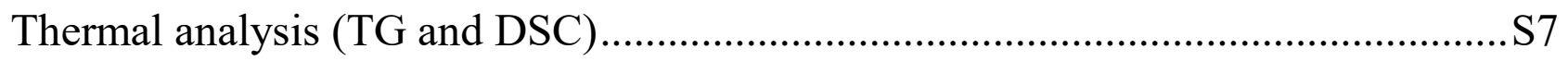

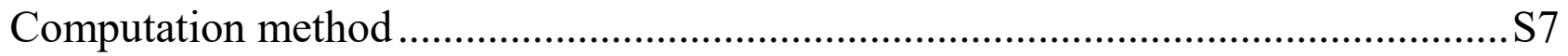

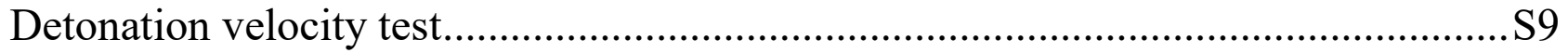

Reference 


\section{Experimental details}

All the materials and chemical reagents with analytical grade were bought from Sinopharm Chemical reagent Beijing Co., Ltd, and used without further purification. IR spectra were measured on a Bruker Equinox 55 infrared spectrometer by using $\mathrm{KBr}$ pellets from 400 to $4000 \mathrm{~cm}^{-1}$ with a resolution of $4 \mathrm{~cm}^{-1}$. Elemental analyses $(\mathrm{C}, \mathrm{H}$ and $\mathrm{N})$ were performed on a Flash EA 1112 fully automatic trace element analyzer. X-ray powder diffraction (XRPD) measurements were performed on a Bruker D8 advance diffractometer at $60 \mathrm{kV}, 300 \mathrm{~mA}$ and $\mathrm{Cu} \mathrm{K} \alpha$ radiation $(\lambda=1.5406$ $\AA$ ), with a scan speed of $5{ }^{\circ} \mathrm{C} \cdot \mathrm{min}^{-1}$ and a step size of $0.02^{\circ}$ in $2 \theta$. The single crystal X-ray diffraction data collections were carried out on a Rigaku AFC-10/Saturn $724^{+} \mathrm{CCD}$ diffractometer with graphite-monochromated Mo Ka radiation $\left(\lambda=0.71073 \AA\right.$ ) using the multi-scan technique. The structures were determined and refined by using SHELXL-2015 ${ }^{1}$ and Olex $2^{2}$ software. The surface morphology was determined by scanning electron microscopy (SEM, S4800, Hitachi, Japan) operating at $15.0 \mathrm{kV}$. Differential scanning calorimeter (DSC) and thermogravimetric analysis (TG) measurement were carried out by using Pyris-1 differential scanning calorimeter and Pyris-1 thermogravimetric analyzer (Perkin Elmer, USA) at the heating rate of $5{ }^{\circ} \mathrm{C} \mathrm{min}^{-1}$ under dry nitrogen atmosphere with flowing rate of $20 \mathrm{~mL} \mathrm{~min}^{-1}$. Impact sensitivity measurement was made using a standard BAM fall hammer. Friction sensitivity measurement was made using a BAM friction tester. Electrostatic Sensitivity measurement was made using EST806F electrostatic power generator. The charge capacitance is $10000 \mathrm{pF}$, the electrode gap length is $0.12 \mathrm{~mm}$. The test energy was given by the formula $\mathrm{E}=1 / 2 \mathrm{CV}^{2}$, where $\mathrm{C}$ is the capacitance of the capacitor in farads (F) and V is charge voltage in volt (V). Samples were tested using the up and down method for each condition, and the electrostatic sensitivity $\left(E_{50}\right)$ for $50 \%$ probability of ignition was calculated.

1,5-Diaminotetrazole was prepared by the reported procedure ${ }^{3}$ and was recrystallized before used in the synthesis. All other chemicals were A.R. grade and could be purchased commercially from without further purification.

$\left[\mathrm{Cu}(\mathrm{DAT})_{3}\right] \mathrm{NO}_{3}$ (light yellow solid and single crystals) was obtained by hydrothermal synthesis of a mixture of $\mathrm{Cu}\left(\mathrm{NO}_{3}\right)_{2} \cdot 3 \mathrm{H}_{2} \mathrm{O}(0.726 \mathrm{~g}, 3 \mathrm{mmol}), 1,5$-diaminotetrazole $(1.2 \mathrm{~g}, 12 \mathrm{mmol}), \mathrm{H}_{3} \mathrm{PO}_{3}(0.164 \mathrm{~g}, 2 \mathrm{mmol})$ and $15 \mathrm{~mL}$ methanol, placed in a sealed $20 \mathrm{~mL}$ Teflon coated reactor and kept heating at $90^{\circ} \mathrm{C}$ for $24 \mathrm{~h}$ and slowly cooled to room temperature $10{ }^{\circ} \mathrm{C}$ per hour. Yield: $0.63 \mathrm{~g}, 49.34 \%$. $T_{\text {dec }}\left(5^{\circ} \mathrm{C} \mathrm{min}^{-1}\right): 223.2{ }^{\circ} \mathrm{C}$; IR $(\mathrm{KBr}): \tilde{v}=3351,3245,1681,1618$, $1569,1313,1127,1059,998,871,701,570 \mathrm{~cm}^{-1}$; elemental analysis $\left(\mathrm{C}_{3} \mathrm{H}_{12} \mathrm{Cu} \mathrm{N}_{19} \mathrm{O}_{3}, 425.86\right)$ : calcd: $\mathrm{C} 8.45, \mathrm{~N} 62.46 \%$; found: C 8.79, N: $61.97 \%$. Impact sensitivity: $1.5 \mathrm{~J}$; friction sensitivity: $84 \mathrm{~N}$; electrostatic sensitivity: $2.0 \mathrm{~J}$.

Caution: Although $\left[\mathrm{Cu}(\mathrm{DAT})_{3}\right] \mathrm{NO}_{3}$ has selective sensitivity and we have not experienced any difficulties in synthesizing and handling it, it may explode under certain conditions. Appropriate safety precautions (safety glasses, face shields, leather coat, and ear plugs) should be taken when preparing and handling, especially when this compound is prepared on a large scale.

\section{$\mathrm{X}$-ray diffraction data}

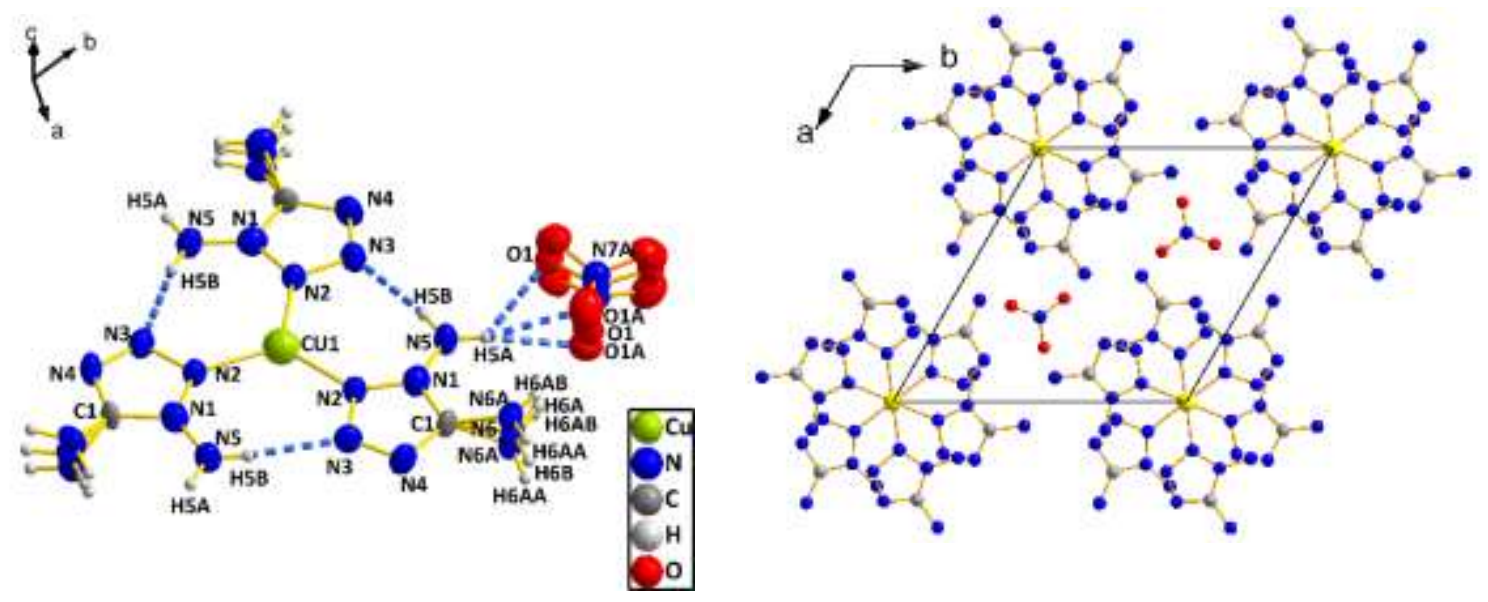


(a)

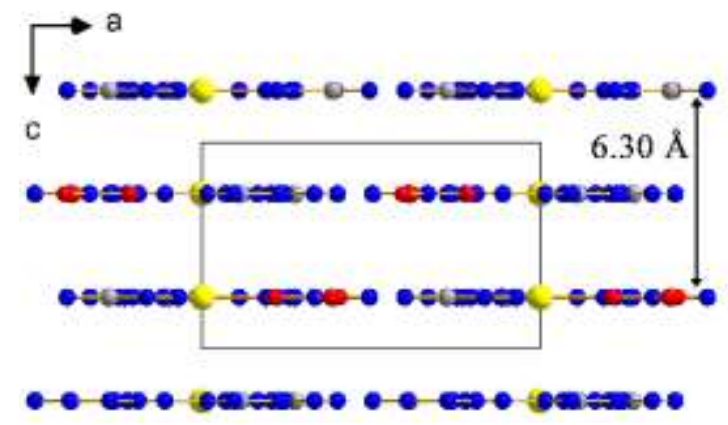

(c) (b)

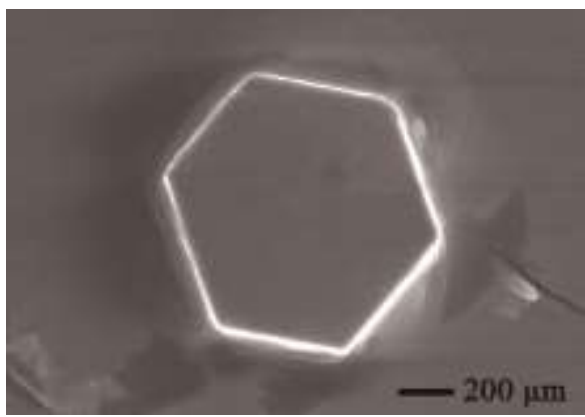

(d)

Figure S1 a) molecular structures and hydrogen bonds of CDN (with disorder); b) packing diagram of CDN along c axis in a unit cell; c) packing diagram of CDN in two planes along c axis; d) the surface morphology of CDN taken by SEM

Table S1 Crystal data and structure refinement for CDN

\begin{tabular}{ll}
\hline Empirical formula & $\mathrm{C}_{3} \mathrm{H}_{12} \mathrm{CuN}_{19} \mathrm{O}_{3}$ \\
\hline Identification code & $\mathrm{CDN}$ \\
Formula weight & 425.86 \\
Temperature/K & 293.1500 \\
Crystal system & hexagonal \\
Space group & $\mathrm{P} 63 / \mathrm{m}$ \\
$\mathrm{a} / \AA$ & $11.8868(17)$ \\
$\mathrm{b} / \AA$ & $11.8868(17)$ \\
$\mathrm{c} / \AA$ & $6.3020(13)$ \\
$\alpha /{ }^{\circ}$ & 90.00 \\
$\beta /{ }^{\circ}$ & 90.00 \\
$\gamma /{ }^{\circ}$ & 120.00 \\
Volume/ $\AA^{3}$ & $771.1(3)$ \\
$Z$ & 2 \\
$\rho_{\text {calc }} / \mathrm{g}$ cm & \\
$\mu$ &
\end{tabular}


Table S2 Bond Lengths for CDN.

\begin{tabular}{|c|c|c|c|c|c|}
\hline Atom & Atom & Length/Å & Atom & Atom & Length/Å \\
\hline $\mathrm{Cu} 1$ & $\mathrm{~N} 2$ & $1.966(4)$ & $\mathrm{C} 1$ & $\mathrm{~N} 1$ & $1.349(7)$ \\
\hline $\mathrm{Cu} 1$ & $\mathrm{~N} 2^{1}$ & $1.966(4)$ & $\mathrm{C} 1$ & $\mathrm{~N}^{2} \mathrm{~A}^{3}$ & $1.418(15)$ \\
\hline $\mathrm{Cu} 1$ & $\mathrm{~N} 2^{2}$ & $1.966(4)$ & $\mathrm{C} 1$ & N6A & $1.418(15)$ \\
\hline $\mathrm{N} 2$ & $\mathrm{~N} 3$ & $1.376(6)$ & N5 & $\mathrm{N} 1$ & $1.326(8)$ \\
\hline $\mathrm{N} 2$ & N1 & $1.326(7)$ & $\mathrm{O} 1$ & N7 & $1.242(9)$ \\
\hline N4 & $\mathrm{N} 3$ & $1.286(7)$ & N6A & $N_{6} A^{3}$ & $0.89(7)$ \\
\hline N4 & $\mathrm{C} 1$ & $1.365(8)$ & O1A & N7A & $1.204(16)$ \\
\hline $\mathrm{C} 1$ & N6 & $1.395(14)$ & & & \\
\hline
\end{tabular}

${ }^{1} 1+\mathrm{Y}-\mathrm{X}, 2-\mathrm{X}, 5 / 2-\mathrm{Z} ;{ }^{2} 2-\mathrm{Y}, 1+\mathrm{X}-\mathrm{Y},+\mathrm{Z} ;{ }^{3}+\mathrm{X},+\mathrm{Y}, 5 / 2-\mathrm{Z}$

Table S3 Bond Angles for CDN

\begin{tabular}{|c|c|c|c|c|c|c|c|}
\hline Atom & Atom & Atom & Angle $/^{\circ}$ & Atom & Atom & Atom & Angle $/^{\circ}$ \\
\hline $\mathrm{N} 2$ & $\mathrm{Cu} 1$ & $\mathrm{~N} 2^{1}$ & 119.999(1) & $\mathrm{O} 1^{4}$ & N7 & $\mathrm{O} 1$ & $120.003(7)$ \\
\hline $\mathrm{N} 2$ & $\mathrm{Cu} 1$ & $\mathrm{~N} 2^{2}$ & $120.001(2)$ & $\mathrm{O} 1^{5}$ & N7 & $\mathrm{O} 1$ & $120.002(8)$ \\
\hline $\mathrm{N} 2^{1}$ & $\mathrm{Cu} 1$ & $\mathrm{~N} 2^{2}$ & $120.000(3)$ & $\mathrm{O} 1^{5}$ & N7 & $\mathrm{O} 1^{4}$ & $119.996(1)$ \\
\hline N3 & $\mathrm{N} 2$ & $\mathrm{Cu} 1$ & 122.1(4) & $\mathrm{N}^{6} \mathrm{~A}^{3}$ & N6A & $\mathrm{C} 1$ & $71.8(14)$ \\
\hline N1 & $\mathrm{N} 2$ & $\mathrm{Cu} 1$ & $130.9(4)$ & $\mathrm{O} 1 \mathrm{~A}^{3}$ & O1A & $\mathrm{N}^{4} \mathrm{~A}^{4}$ & $51.3(19)$ \\
\hline N1 & $\mathrm{N} 2$ & N3 & 107.1(5) & $\mathrm{O} 1 \mathrm{~A}^{3}$ & O1A & N7A & $79(2)$ \\
\hline N3 & N4 & $\mathrm{C} 1$ & $106.6(5)$ & N7A & O1A & $\mathrm{N} \mathrm{A}^{4}$ & $27(3)$ \\
\hline N4 & $\mathrm{N} 3$ & $\mathrm{~N} 2$ & $110.2(5)$ & $\mathrm{O} 1 \mathrm{~A}^{4}$ & N7A & $\mathrm{O} 1 \mathrm{~A}^{3}$ & $85(3)$ \\
\hline N4 & $\mathrm{C} 1$ & N6 & $123.6(13)$ & O1A & N7A & $01 A^{3}$ & $50(3)$ \\
\hline N4 & $\mathrm{C} 1$ & $\mathrm{~N}_{6} \mathrm{~A}^{3}$ & $123.3(12)$ & $\mathrm{O} 1 \mathrm{~A}^{6}$ & N7A & $01 A^{3}$ & $85(3)$ \\
\hline $\mathrm{N} 4$ & $\mathrm{C} 1$ & N6A & $123.3(12)$ & $\mathrm{O} 1 \mathrm{~A}^{5}$ & N7A & $01 A^{6}$ & $50(3)$ \\
\hline N6 & $\mathrm{C} 1$ & $\mathrm{~N}_{6} \mathrm{~A}^{3}$ & $18.3(14)$ & $\mathrm{O} 1 \mathrm{~A}^{7}$ & N7A & $01 A^{3}$ & $120.5(15)$ \\
\hline N1 & $\mathrm{C} 1$ & N4 & 109.1(4) & $\mathrm{O} 1 \mathrm{~A}^{7}$ & N7A & $\mathrm{O}_{1} \mathrm{~A}^{6}$ & $120.5(15)$ \\
\hline N1 & $\mathrm{C} 1$ & N6 & $127.3(13)$ & $\mathrm{O} 1 \mathrm{~A}^{7}$ & N7A & O1A & 116.1(15) \\
\hline N1 & $\mathrm{C} 1$ & $\mathrm{~N}^{2} \mathrm{~A}^{3}$ & $123.5(11)$ & O1A & N7A & $\mathrm{O}_{1} \mathrm{~A}^{6}$ & $120.5(15)$ \\
\hline N1 & $\mathrm{C} 1$ & N6A & $123.5(11)$ & $\mathrm{O}_{1} \mathrm{~A}^{5}$ & N7A & $01 \mathrm{~A}^{3}$ & $120.5(15)$ \\
\hline N6A & $\mathrm{C} 1$ & $\mathrm{~N}^{2} \mathrm{~A}^{3}$ & $36(3)$ & $\mathrm{O}_{1} \mathrm{~A}^{5}$ & N7A & O1A & $116.1(15)$ \\
\hline $\mathrm{N} 2$ & N1 & $\mathrm{C} 1$ & 107.1(5) & $\mathrm{N} \mathrm{A}^{4}$ & N7A & $01 A^{3}$ & $51.3(19)$ \\
\hline N5 & N1 & $\mathrm{N} 2$ & $129.1(5)$ & $\mathrm{N} \mathrm{A}^{4}$ & N7A & $\mathrm{O}_{1} \mathrm{~A}^{6}$ & $51.3(19)$ \\
\hline N5 & N1 & $\mathrm{C} 1$ & $123.9(5)$ & $\mathrm{N} 7 \mathrm{~A}^{4}$ & N7A & O1A & $101(2)$ \\
\hline
\end{tabular}

Table S4 Torsion Angles for CDN

\begin{tabular}{llllllllll}
\hline $\mathbf{A}$ & $\mathbf{B}$ & $\mathbf{C}$ & $\mathbf{D}$ & Angle $^{\circ}$ & $\mathbf{A}$ & $\mathbf{B}$ & $\mathbf{C}$ & $\mathbf{D}$ & Angle $^{\circ}$ \\
\hline $\mathrm{Cu} 1$ & $\mathrm{~N} 2$ & $\mathrm{~N} 3$ & $\mathrm{~N} 4$ & 180.0 & $\mathrm{~N} 1$ & $\mathrm{C} 1$ & $\mathrm{~N} 6 \mathrm{~A}$ & $\mathrm{~N} 6 \mathrm{~A}^{1}$ & $-102.6(11)$ \\
$\mathrm{Cu} 1$ & $\mathrm{~N} 2$ & $\mathrm{~N} 1$ & $\mathrm{C} 1$ & 180.0 & $\mathrm{~N} 6 \mathrm{~A}$ & $\mathrm{C} 1$ & $\mathrm{~N} 1$ & $\mathrm{~N} 2$ & $-158.0(17)$ \\
$\mathrm{Cu} 1$ & $\mathrm{~N} 2$ & $\mathrm{~N} 1$ & $\mathrm{~N} 5$ & 0.0 & $\mathrm{~N} 6 \mathrm{~A}^{1}$ & $\mathrm{C} 1$ & $\mathrm{~N} 1$ & $\mathrm{~N} 2$ & $158.0(17)$
\end{tabular}




\begin{tabular}{|c|c|c|c|c|c|c|c|c|c|}
\hline N4 & $\mathrm{C} 1$ & N1 & $\mathrm{N} 2$ & 0.0 & $\mathrm{~N} \mathrm{~A}^{1}$ & $\mathrm{C} 1$ & N1 & N5 & $-22.0(17)$ \\
\hline N4 & $\mathrm{C} 1$ & N1 & N5 & 180.0 & N6A & $\mathrm{C} 1$ & N1 & N5 & $22.0(17)$ \\
\hline N4 & $\mathrm{C} 1$ & N6A & $\mathrm{N}^{2} \mathrm{~A}^{1}$ & $102.5(10)$ & $\mathrm{O}_{1} \mathrm{~A}^{1}$ & O1A & N7A & $\mathrm{O} 1 \mathrm{~A}^{2}$ & $-52(3)$ \\
\hline N3 & $\mathrm{N} 2$ & N1 & $\mathrm{C} 1$ & 0.0 & $\mathrm{O} 1 \mathrm{~A}^{1}$ & O1A & N7A & $01 A^{3}$ & $-109(4)$ \\
\hline N3 & $\mathrm{N} 2$ & $\mathrm{~N} 1$ & N5 & 180.0 & $\mathrm{O} 1 \mathrm{~A}^{1}$ & O1A & N7A & $\mathrm{O} 1 \mathrm{~A}^{4}$ & $52(3)$ \\
\hline N3 & N4 & $\mathrm{C} 1$ & N6 & 180.0 & $01 A^{1}$ & O1A & N7A & $01 A^{5}$ & $109(4)$ \\
\hline N3 & N4 & $\mathrm{C} 1$ & N1 & 0.0 & $\mathrm{O} 1 \mathrm{~A}^{1}$ & $\mathrm{O} 1 \mathrm{~A}$ & N7A & $\mathrm{N}^{2} \mathrm{~A}^{2}$ & $0.00(4)$ \\
\hline N3 & N4 & $\mathrm{C} 1$ & $\mathrm{~N}^{1} \mathrm{~A}^{1}$ & $-158.0(17)$ & $\mathrm{N}^{2} \mathrm{~A}^{2}$ & O1A & N7A & $\mathrm{O} 1 \mathrm{~A}^{1}$ & $0.00(9)$ \\
\hline N3 & N4 & $\mathrm{C} 1$ & N6A & $158.0(17)$ & $\mathrm{N}^{2} \mathrm{~A}^{2}$ & $\mathrm{O} 1 \mathrm{~A}$ & N7A & $\mathrm{O} 1 \mathrm{~A}^{2}$ & $-52(3)$ \\
\hline $\mathrm{C} 1$ & N4 & N3 & $\mathrm{N} 2$ & 0.0 & $\mathrm{~N}^{2} \mathrm{~A}^{2}$ & O1A & N7A & $01 A^{5}$ & $109(4)$ \\
\hline N6 & $\mathrm{C} 1$ & N1 & $\mathrm{N} 2$ & 180.0 & $\mathrm{~N}_{7} \mathrm{~A}^{2}$ & O1A & N7A & $\mathrm{O} 1 \mathrm{~A}^{4}$ & $52(3)$ \\
\hline N6 & $\mathrm{C} 1$ & N1 & N5 & 0.0 & $\mathrm{~N}^{2} \mathrm{~A}^{2}$ & O1A & N7A & $\mathrm{O} 1 \mathrm{~A}^{3}$ & $-109(4)$ \\
\hline N1 & $\mathrm{N} 2$ & N3 & N4 & 0.0 & & & & & \\
\hline
\end{tabular}

${ }^{1}+\mathrm{X},+\mathrm{Y}, 5 / 2-\mathrm{Z} ;{ }^{2} 1+\mathrm{Y}-\mathrm{X}, 1-\mathrm{X}, 5 / 2-\mathrm{Z} ;{ }^{3} 1+\mathrm{Y}-\mathrm{X}, 1-\mathrm{X},+\mathrm{Z} ;{ }^{4} 1-\mathrm{Y},+\mathrm{X}-\mathrm{Y}, 5 / 2-\mathrm{Z} ;{ }^{5} 1-\mathrm{Y},+\mathrm{X}-\mathrm{Y},+\mathrm{Z}$

Table S5 Hydrogen Bonds for CDN

\begin{tabular}{lllll}
\hline $\mathbf{D}-\mathbf{H} \cdots \mathbf{A}$ & $\mathbf{D}-\mathbf{H} / \mathbf{\AA}$ & $\mathbf{H} \cdots \mathbf{A} / \AA$ & $\mathbf{D} \cdots \mathbf{A} / \AA$ & Angles $^{\circ}$ \\
\hline $\mathrm{N} 5-\mathrm{H} 5 \mathrm{~A} \cdots \mathrm{O} 1$ & 0.84 & 2.18 & $3.019(13)$ & 178.00 \\
$\mathrm{~N} 5-\mathrm{H} 5 \mathrm{~A} \cdots \mathrm{O} 1 \mathrm{~A}$ & 0.84 & 2.22 & $3.04(2)$ & 164.00 \\
$\mathrm{~N} 5-\mathrm{H} 5 \mathrm{~A} \cdots \mathrm{O} 1{ }^{1}$ & 0.84 & 2.59 & $3.151(15)$ & 125.00 \\
$\mathrm{~N} 5-\mathrm{H} 5 \mathrm{~A} \cdots \mathrm{O}^{\circ}{ }^{2}$ & 0.84 & 2.22 & $3.04(2)$ & 164.00 \\
$\mathrm{~N} 5-\mathrm{H} 5 \mathrm{~B} \cdots \mathrm{N}^{3}$ & 0.84 & 2.17 & $3.002(10)$ & 171.00 \\
\hline
\end{tabular}

${ }^{1} 1-\mathrm{X}+\mathrm{Y}, 1-\mathrm{X}, \mathrm{Z},{ }^{2} \mathrm{X}, \mathrm{Y}, 5 / 2-\mathrm{Z},{ }^{3} 2-\mathrm{Y}, 1+\mathrm{X}-\mathrm{Y}, \mathrm{Z}$

\section{Hirshfeld Surface Analysis}

There are many types of weak interactions existing in CDN molecule. According to Figure S2a, the weak interactions among nitrogen atoms contribute through $\mathrm{N}-\mathrm{NH}_{2}$ and the nitrogen atoms in tetrazole rings facing $\mathrm{N}-\mathrm{NH}_{2}$. Figure $\mathbf{S 2 b}$ is the finger print plot of Hirshfeld surface analysis. Figure S2c plots the proportion of different interactions in a pie chart. The proportion of interactions among nitrogen atoms is $13.5 \%$ which is the only type of $\pi$-interaction in CDN molecule. These $\pi$-interactions are weak so that the thermal vibration of nitrate ions and $\mathrm{N}-\mathrm{NH}_{2}$ (disorder in the crystal data) are captured by single-crystal X-ray diffraction analysis. It is the factor that contributes to the extremely high impact sensitivity.
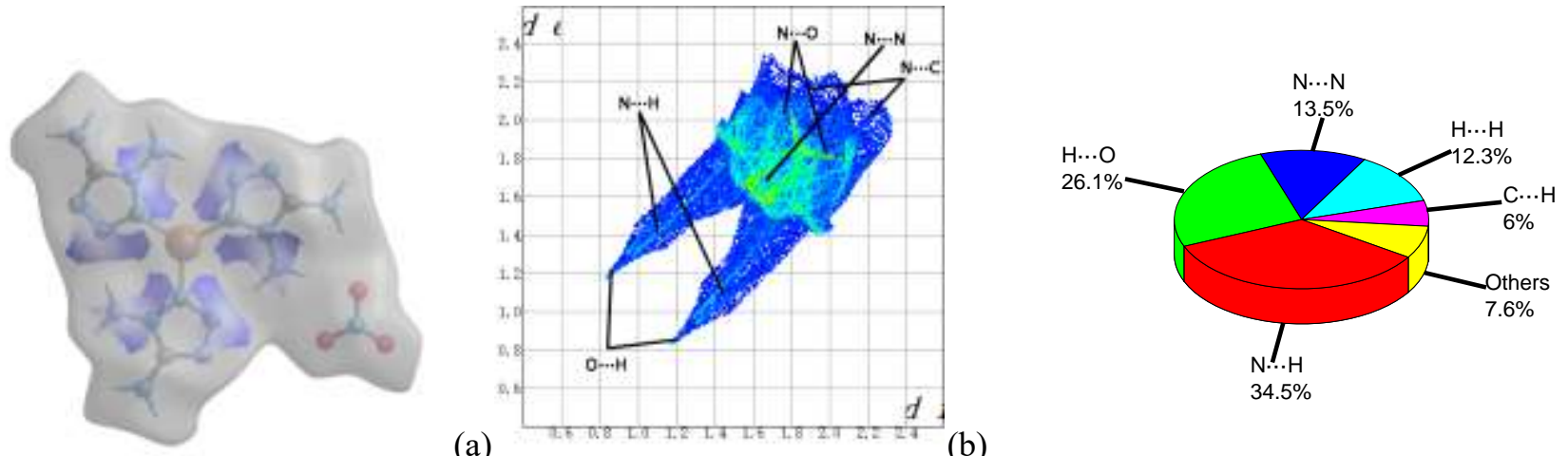

(a)

Figure S2 a) the Hirshfeld surface of $\mathrm{N} \cdots \mathrm{N}$ in $\mathrm{CDN}$ molecule; b) the finger print plot of Hirshfeld surface analysis; $c$ ) the pie chart of the 


\section{X-ray powder diffraction (XRPD)}

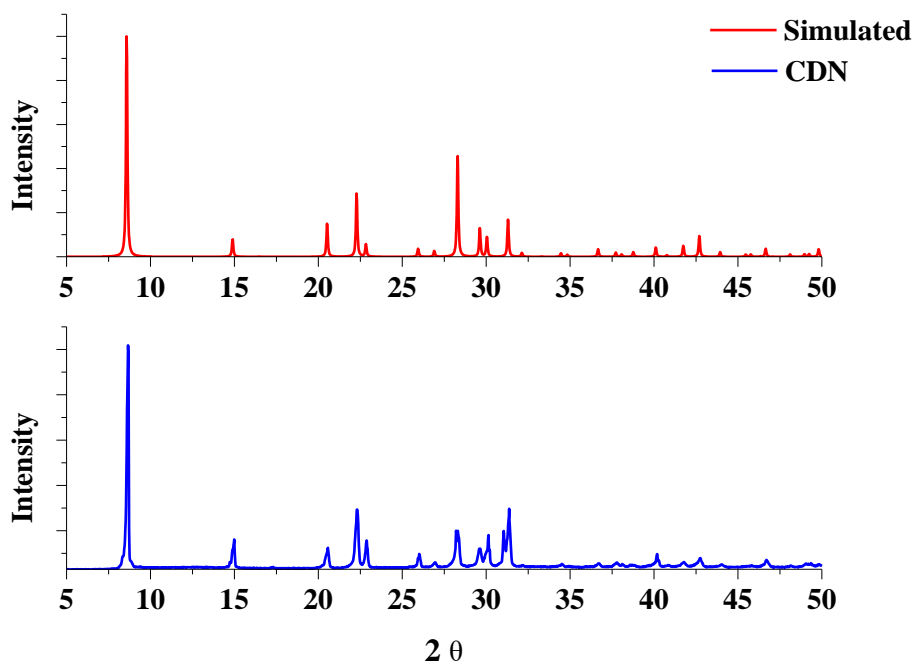

Figure S3 X-ray powder diffraction (XRPD) curve of CDN

\section{Thermal analysis (TG and DSC)}

In the DSC curve of CDN, an intensive exothermic process can be seen at $223.2 \sim 249.5^{\circ} \mathrm{C}$ with a sharp exothermic peak can be seen at $238.5^{\circ} \mathrm{C}$. As TG-DTG curves showing, the first mass loss occurs very rapidly and the mass loss is $59.8 \%$ of total. The tremendous energy is released during the first exothermic process.

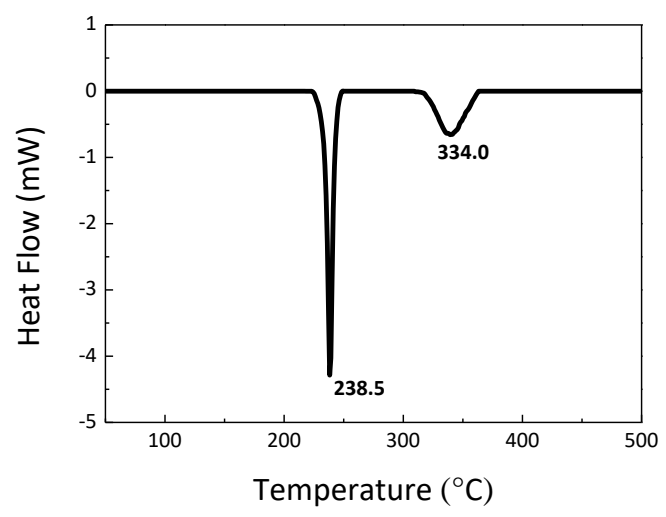

(a)

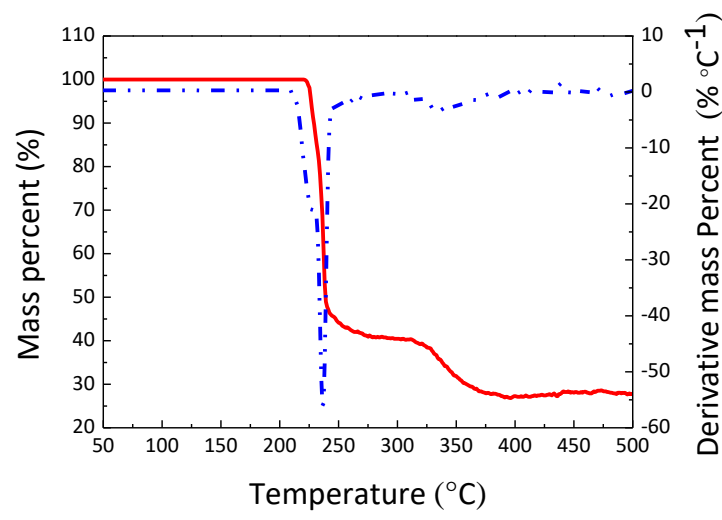

Figure S4 a)DSC curve of CDN; b) TG-DTG curves of CDN

\section{Computation method}

The structure of CDN was optimized using the $\mathrm{CASTEP}^{4}$ code of Materials Studio 2018 program package. Perdew Burke Ernzerhof $\left(\mathrm{PBE}^{5}\right)$ variant of the generalized gradient approximation $\left(\mathrm{GGA}^{6}\right)$ is used to calculate the exchangecorrelation energy. The total energy of the system converges in $5.0 \times 10^{-6} \mathrm{eV}_{\text {atom }}{ }^{-1}$, while the maximum forces on the atoms are $0.01 \mathrm{eV} \AA^{-1}$. The displacement of atoms is under $5.0 \times 10^{-4} \AA$. All the electrons are included in double numerical plus polarization basis set, DNP. After a series of tests, the most efficient k-points sampling grid is $4 \times 4 \times 5$ and cut-off energy is $600 \mathrm{eV}$. The optimized molecular structure is shown in Figure S5, and selected bond lengths and bond angles of theoretical calculations are listed in Table S6 and Table S7. Table S8 is the list of Mulliken bond orders of CDN. The structures of TATB and FOX-7 were also optimized with the same function with the same convergence criteria. The k-points sampling grid for TATB and FOX-7 are $7 \times 6 \times 6$ and $8 \times 7 \times 7$, respectively. All three compounds' elastic constants were calculated by the same method with the same convergence criteria on basis of the optimized geometries. 

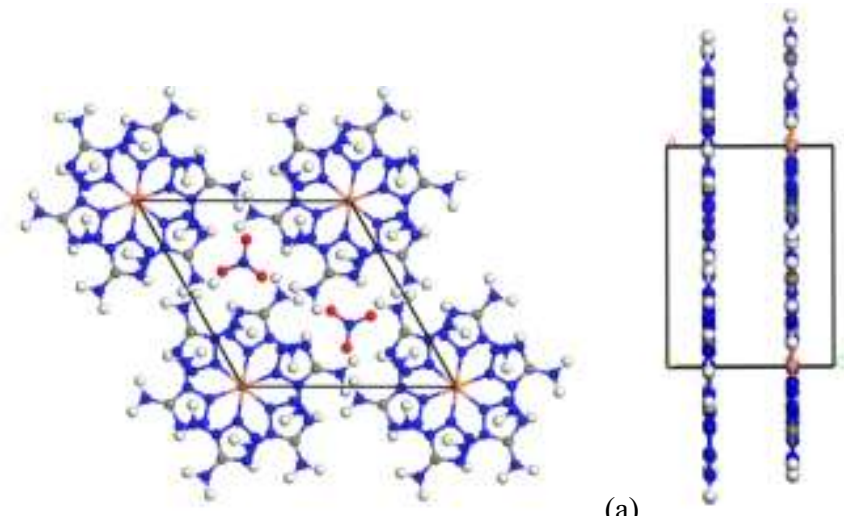

(a)

(b)

Figure S5 (a) The optimized structure of CDN from c axis; (b) the optimized structure of CDN from b axis

Table S6 The bond length for optimized structure of CDN

\begin{tabular}{|c|c|c|c|c|c|}
\hline Atom & Atom & Length/Å & Atom & Atom & Length/Å \\
\hline $\mathrm{Cu} 1$ & $\mathrm{~N} 2$ & 1.9591 & N6 & $\mathrm{C} 1$ & 1.3377 \\
\hline $\mathrm{N} 2$ & N3 & $1.376(6)$ & $\mathrm{O} 1$ & N7 & 1.2615 \\
\hline N1 & N5 & 1.3465 & N5 & H5A & 1.0200 \\
\hline N1 & $\mathrm{C} 1$ & 1.3585 & N5 & H5B & 1.0300 \\
\hline $\mathrm{N} 2$ & $\mathrm{~N} 3$ & 1.3241 & N6 & H6A & 1.0200 \\
\hline $\mathrm{N} 3$ & N4 & 1.3294 & N6 & H6B & 1.0300 \\
\hline N4 & $\mathrm{C} 1$ & 1.3489 & & & \\
\hline
\end{tabular}

Table S7 The bond angle for optimized structure of CDN

\begin{tabular}{llllllll}
\hline Atom & Atom & Atom & Angle $^{\circ}$ & Atom & Atom & Atom & Angle $^{\circ}$ \\
\hline N2 & Cu1 & N2 & 120.00 & N1 & C1 & N6 & 123.98 \\
N2 & N1 & N5 & 123.40 & N4 & C1 & N6 & 128.75 \\
N2 & N1 & C1 & 108.43 & N1 & N5 & H5A & 117.00 \\
N5 & N1 & C1 & 128.17 & N1 & N5 & H5B & 120.00 \\
Cu1 & N2 & N1 & 128.83 & H5A & N5 & H5B & 123.00 \\
Cu1 & N2 & N3 & 124.96 & C1 & N6 & H6A & 120.00 \\
N1 & N2 & N3 & 106.22 & C1 & N6 & H6B & 123.00 \\
N2 & N3 & N4 & 111.03 & H6A & N6 & H6B & 117.00 \\
N3 & N4 & C1 & 107.05 & O1 & N7 & O1_a & 120.00 \\
N1 & C1 & N4 & 107.27 & & & & \\
\hline
\end{tabular}




\section{Detonation velocity test}

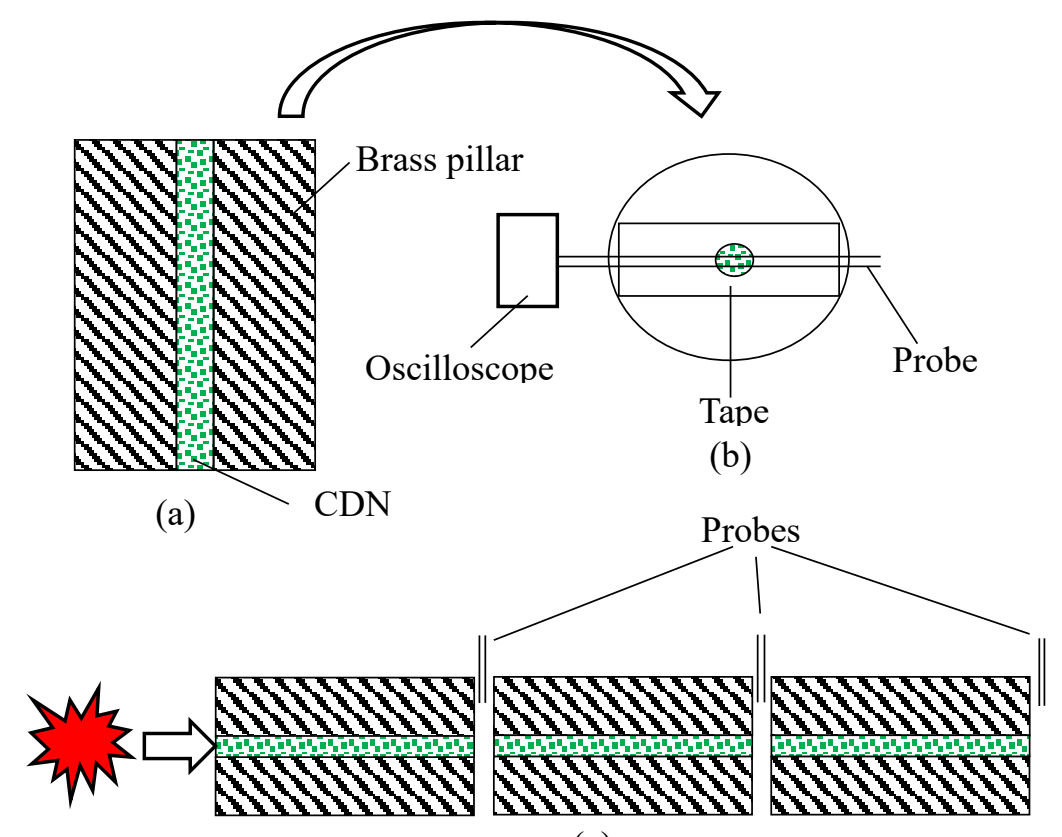

(c)

Figure S6 a) Brass tube filled with CDN; b) the assembling of probes; c) connecting the brass tubes in series

First of all, CDN is filled in a brass pillar (Figure S6a). Thereafter, on the top of a brass pillar, a pair of probes are fixed by tape and connect to an oscilloscope (Figure S6b). Next, the brass pillars are connected and fixed in series (Figure S6c). Eventually, an external stimulus is used to initiate the CDN in the first brass pillar (Figure S6c). During the detonation, a part of products exist as ionic state and is electrical conductivity. Meanwhile, the oscilloscope will record a signal. Recording the time between two signals $\Delta \mathrm{t}(\Delta \mathrm{t}=3.52 \mu \mathrm{s})$, detonation velocity can be determined via $\mathrm{D}=\mathrm{L} / \Delta \mathrm{t}$. The final result is an average of measurements repeated for four times. The loading density of CDN $\left(1.81 \mathrm{~g} \mathrm{~cm}^{-}\right.$ ${ }^{3}$ ) can be determined by $\rho=\left(m_{1}-m_{2}\right) / V$, where $m_{1}$ is the mass of the brass pillar filled with CDN; $m_{2}$ is the mass of the brass pillar, $\mathrm{V}=\pi \mathrm{d}^{2} / 4$ is the volume of $\mathrm{CDN}$ in the brass pillar.

\section{Reference}

1. Sheldrick, G. M., SHELXT - Integrated space-group and crystal-structure determination. Acta Crystallographica a-Foundation and Advances 2015, 71, 3-8.

2. Dolomanov, O. V.; Bourhis, L. J.; Gildea, R. J.; Howard, J. A. K.; Puschmann, H., OLEX2: a complete structure solution, refinement and analysis program. Journal of Applied Crystallography 2009, 42, 339-341.

3. Gaponik, P. N.; Karavai, V. P., Synthesis and properties of 1,5-diaminotetrazole. Chemistry of Heterocyclic Compounds 1984, 20 (12), 1388-1391.

4. CLARK; Stewart, J.; SEGALL; Matthew, D.; PICKARD; Chris, J.; HASNIP; Phil, J.; PROBERT; Matt, I. J., First principles methods using CASTEP. Zeitschrift für Kristallographie - Crystalline Materials 2005, 220 (5/6), 567570.

5. Perdew, J. P.; Burke, K.; Ernzerhof, M., Generalized gradient approximation made simple. Physical review letters 1996, 77 (18), 3865.

6. Perdew, J. P.; Wang, Y., ACCURATE AND SIMPLE ANALYTIC REPRESENTATION OF THE ELECTRONGAS CORRELATION-ENERGY. Physical Review B 1992, 45 (23), 13244-13249. 